\title{
Exfoliation and Noncovalent Functionalization of Graphene Surface with Poly-N-Vinyl-2-Pyrrolidone by In Situ Polymerization
}

\author{
Suguna Perumal ${ }^{\dagger}$, Raji Atchudan ${ }^{*}+\left(\mathbb{D}\right.$, Thomas Nesakumar Jebakumar Immanuel Edison ${ }^{\dagger}$, Jae-Jin Shim * \\ and Yong Rok Lee*
}

check for

updates

Citation: Perumal, S.; Atchudan, R.; Edison, T.N.J.I.; Shim, J.-J.; Lee, Y.R. Exfoliation and Noncovalent Functionalization of Graphene Surface with Poly-N-Vinyl-2Pyrrolidone by In Situ Polymerization. Molecules 2021, 26, 1534. https://doi.org/10.3390/ molecules26061534

Academic Editor: Raffaello Papadakis

Received: 19 February 2021

Accepted: 9 March 2021

Published: 11 March 2021

Publisher's Note: MDPI stays neutral with regard to jurisdictional claims in published maps and institutional affiliations.

Copyright: (c) 2021 by the authors. Licensee MDPI, Basel, Switzerland. This article is an open access article distributed under the terms and conditions of the Creative Commons Attribution (CC BY) license (https:/ / creativecommons.org/licenses/by/ $4.0 /)$.
School of Chemical Engineering, Yeungnam University, Gyeongsan 38541, Korea; suguna.perumal@gmail.com (S.P.); jebakumar84@yu.ac.kr (T.N.J.I.E.)

* Correspondence: atchudanr@yu.ac.kr (R.A.); jjshim@yu.ac.kr (J.-J.S.); yrlee@yu.ac.kr (Y.R.L.)

† These authors contributed equally to this work.

\begin{abstract}
Heteroatom functionalization on a graphene surface can endow the physical and structural properties of graphene. Here, a one-step in situ polymerization method was used for the noncovalent functionalization of a graphene surface with poly- $N$-vinyl-2-pyrrolidone (PNVP) and the exfoliation of graphite into graphene sheets. The obtained graphene/poly- $N$-vinyl pyrrolidone (GPNVP) composite was thoroughly characterized. The surface morphology of GPNVP was observed using field emission scanning electron microscopy and high-resolution transmission electron microscopy. Raman spectroscopy and X-ray diffraction studies were carried out to check for the exfoliation of graphite into graphene sheets. Thermogravimetric analysis was performed to calculate the amount of PNVP on the graphene surface in the GPNVP composite. The successful formation of the GPNVP composite and functionalization of the graphene surface was confirmed by various studies. The cyclic voltammetry measurement at different scan rates $(5-500 \mathrm{mV} / \mathrm{s})$ and electrochemical impedance spectroscopy study of the GPNVP composite were performed in the typical three-electrode system. The GPNVP composite has excellent rate capability with the capacitive property. This study demonstrates the one-pot preparation of exfoliation and functionalization of a graphene surface with the heterocyclic polymer PNVP; the resulting GPNVP composite will be an ideal candidate for various electrochemical applications.
\end{abstract}

Keywords: exfoliation of graphite; graphene; noncovalent functionalization; in situ polymerization; cyclic voltammetry

\section{Introduction}

One of the most studied materials is graphene, where carbon atoms are arranged in a honeycomb lattice structure [1,2]. A one-atom-thick single-layer of carbon was peeled from graphite in 2004 by A. K. Geim and K. S. Novoselov [2]. Graphene is the world's strongest and thinnest material, and if used with other materials, it enhances the strength of the materials. Thus, graphene is used in automobiles and building materials [3,4]. Graphene is a highly conductive material and is thus used in microelectronic applications and mobile devices [5,6]. Graphene has a high surface-area-to-volume ratio and is thus used for energy storage applications [7-9]. Furthermore, graphene is used in coating, sensor, water treatment, and catalyst applications [10-16]. Because of these extraordinary properties and their applications, researchers were urged to focus on the preparation of graphene. From 3D graphite, 2D graphene was derived by many methods. The methods includes mechanical exfoliation [17], chemical oxidation [18], pyrolysis [19], chemical vapor deposition [20,21], molecular assembly [22], and ultrasonic exfoliation [23]. Among these methods, ultrasonic exfoliation (liquid-phase exfoliation) shows promising results indicating a high yield of graphene [24,25]. At first, by liquid-phase exfoliation, graphite was exfoliated into graphene using high-boiling solvents such as N-methyl pyrrolidone $[23,26]$. However, this leads to the reaggregation of graphene sheets. These difficulties were 
solved using surfactants [27]. After this, research focused on the use of appropriate surfactants $[23,28-30]$ on graphene surfaces, which can be utilized in specific applications such as coating [31] and the preparation of graphene composites [32]. Recently, we reported stable graphene dispersions in ethanol, isopropyl alcohol, and methanol, using polypyridine- and polystyrene-based block copolymers [33-35]. Adhesion studies between graphene surfaces and monomers were investigated using atomic force microscopy [36]. Monomers with nitrogen substituents showed high adhesion values towards graphene surfaces. Thus, nitrogen substituent monomers such as vinyl pyridine were selected to prepare polypyridine-based block copolymers. The prepared polymers were utilized to disperse graphene in different solvents [33-35]. In these works, we confirmed that the nitrogen in polymers plays a vital role in interactions with graphene surfaces. Hence, here we utilized heterocyclic $N$-vinyl2-pyrrolidone (NVP) monomer, which has nitrogen and oxygen atoms. It was assumed that the oxygen atom might also be involved in the interaction with graphene, in addition to the nitrogen atom that might enhance the stability of graphene dispersion. This was believed for stable graphene dispersion with poly- $N$-vinyl-2-pyrrolidone (PNVP). Many reports are available on the fabrication or functionalization of graphene surfaces using NVP [37-40]. However, many of them include the preparation of graphene dispersions using graphene derivatives, such as graphene oxide and reduced graphene oxide [39,40]. Only a few reports are available on the exfoliation of graphite [37,38], which consists of many steps, including the exfoliation of graphite, the preparation of polyvinyl pyrrolidone, and the preparation of graphene dispersions. Hence, we propose a facile one-step method to prepare graphene/poly- $N$-vinyl pyrrolidone (GPNVP) composite. Graphite powder was directly exfoliated into graphene and stabilized with PNVP by in situ polymerization of the NVP monomer. Further electrochemical studies were carried out for GPNVP composite in the typical three-electrode system. The cyclic voltammetry (CV) measurement of the GPNVP composite was performed at different scan rates $(5-500 \mathrm{mV} / \mathrm{s})$ and $\mathrm{CV}$ measurements up to 1000 cycles were carried out to reveal the stability of the GPNVP composite.

\section{Results and Discussion}

The functionalization of graphene surfaces with PNVP polymer was achieved by in situ polymerization of the NVP monomer. The graphite powder (GP) was directly used for polymerization using the NVP monomer by sonication. GP and the obtained GPNVP composite were characterized using various physicochemical techniques to compare the surface morphologies and chemical compositions and to confirm the successful formation of the GPNVP composite. Field emission scanning electron microscopy (FESEM) and highresolution transmission electron microscopy (HRTEM) measurements were performed to study the surface morphologies of GP and GPNVP composite. Figures S1 and S2 show the FESEM images of GP and their elemental mapping, respectively. The images reveal the smooth surfaces of GP and a particle size possibly in the few tens of micrometers. The size of the GP was analyzed at a maximum of $\sim 48 \mu \mathrm{m}$ to a minimum of $\sim 3 \mu \mathrm{m}$ in lateral size using ImageJ software. The FESEM images at different magnifications reveal the thickness of GP that suggests the presence of many layers of graphene sheets. The energy-dispersive X-ray spectroscopy (EDS) spectrum reveals the presence of carbon $(\mathrm{C})$ and oxygen $(\mathrm{O})$ atoms on the GP surface (Figure S1e). Further, the existence of $\mathrm{C}$ and $\mathrm{O}$ is confirmed from the elemental mapping images (Figure S2). The surface of GP is covered mainly with $C$ and with a trace amount of $\mathrm{O}$ atoms. The FESEM images of the GPNVP composite at different magnifications are shown in Figure 1. Figure 1a,b shows the FESEM images of the GPNVP composite at low magnifications; the images manifest the smooth surface of graphene sheets. The lateral size of graphene sheets will be a few micrometers with a few layers of graphene, which are evident from the images in Figure 1c,d. Using ImageJ software, the sizes of graphene sheets in GPNVP composites were measured at a maximum of $\sim 5 \mu \mathrm{m}$ to a minimum of $\sim 70 \mathrm{~nm}$ in lateral size. Figure 1e depicts the EDS spectrum of the GPNVP composite that divulges the presence of atoms such as $\mathrm{C}$, nitrogen $(\mathrm{N})$, and $\mathrm{O}$. Further, the 
elemental mapping of the GPNVP composite reveals the presence of $\mathrm{C}, \mathrm{N}$, and $\mathrm{O}$ atoms (Figure 2).
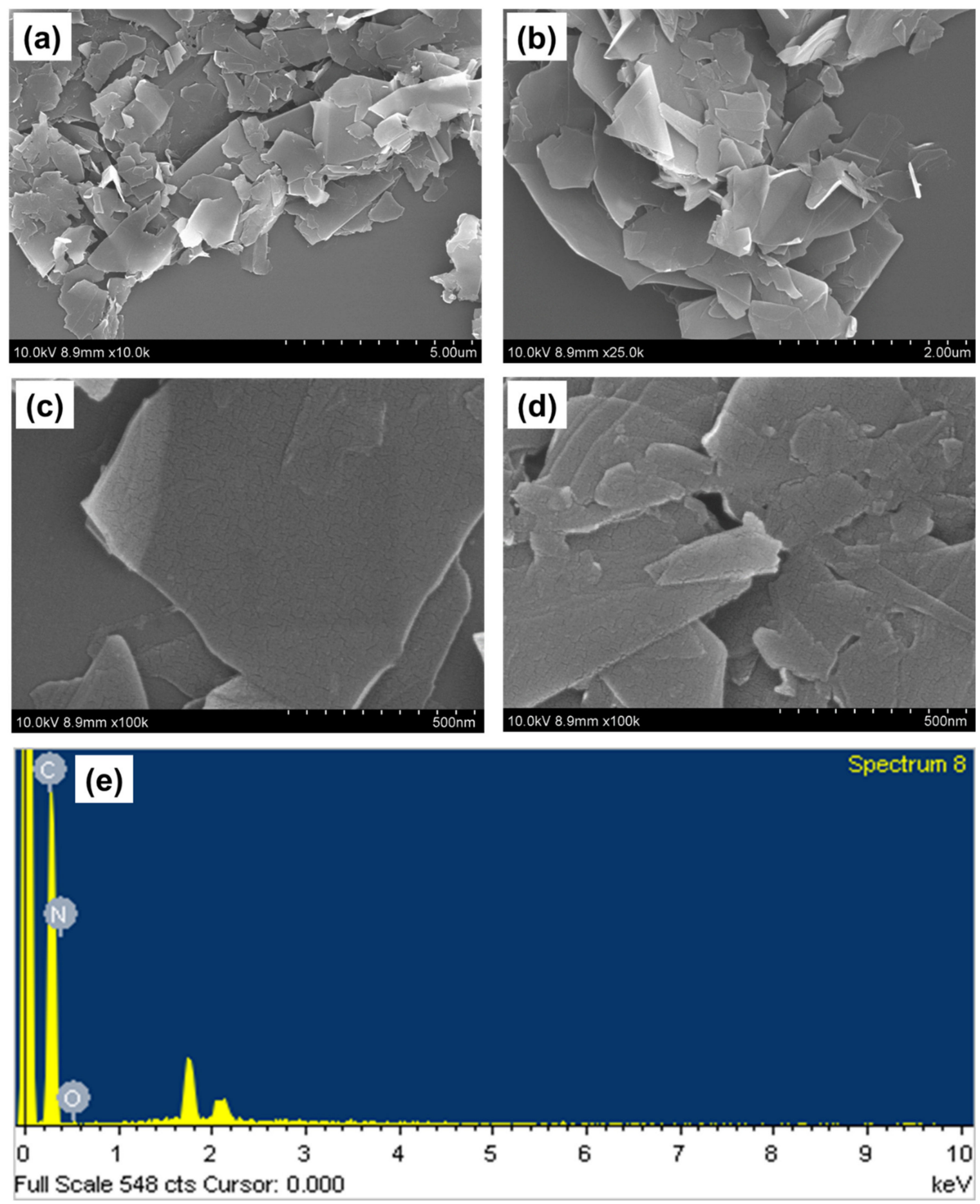

Figure 1. (a-d) FESEM images of graphene/poly- $N$-vinyl pyrrolidone (GPNVP) composite at different magnifications. (e) EDS spectrum of GPNVP composite. 


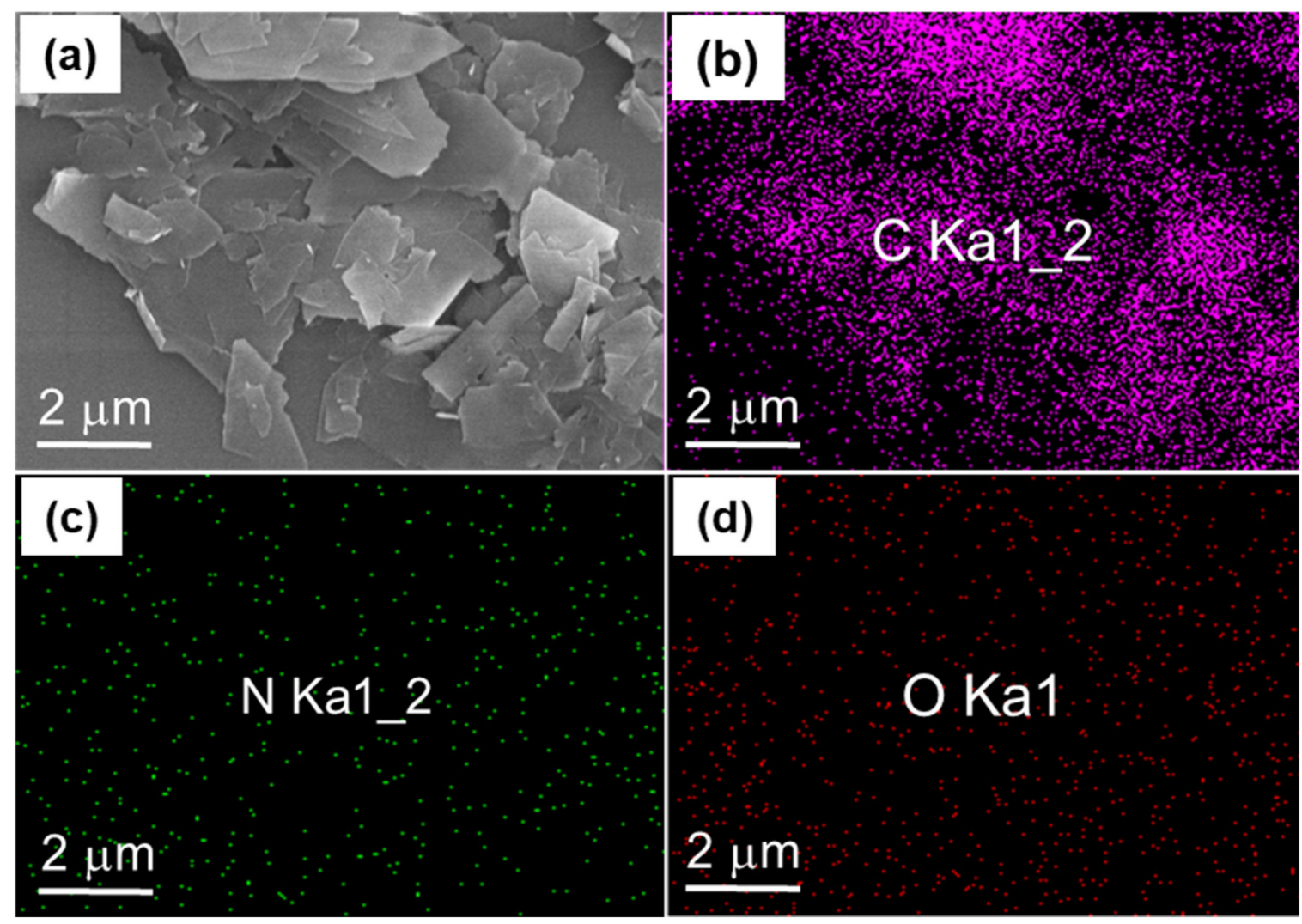

Figure 2. FESEM image of GPNVP composite (a) and the corresponding elemental mappings for (b) carbon, (c) nitrogen, and (d) oxygen.

Further, the surface morphologies of GP and GPNVP composite were studied using HRTEM measurements. Figure S3 shows the HRTEM images of GP that reveal the many layers of twisted graphene sheets (Figure S3a,b). On the other hand, the lattice fringe is clear from Figure $3 a$, which suggests few-layered graphene in the GPNVP composite. Figure $3 b$ shows a very thin and small-sized graphene sheet. This specifies that in situ polymerization helps in the functionalization of graphene surfaces with PNVP and exfoliates graphite into graphene layers.
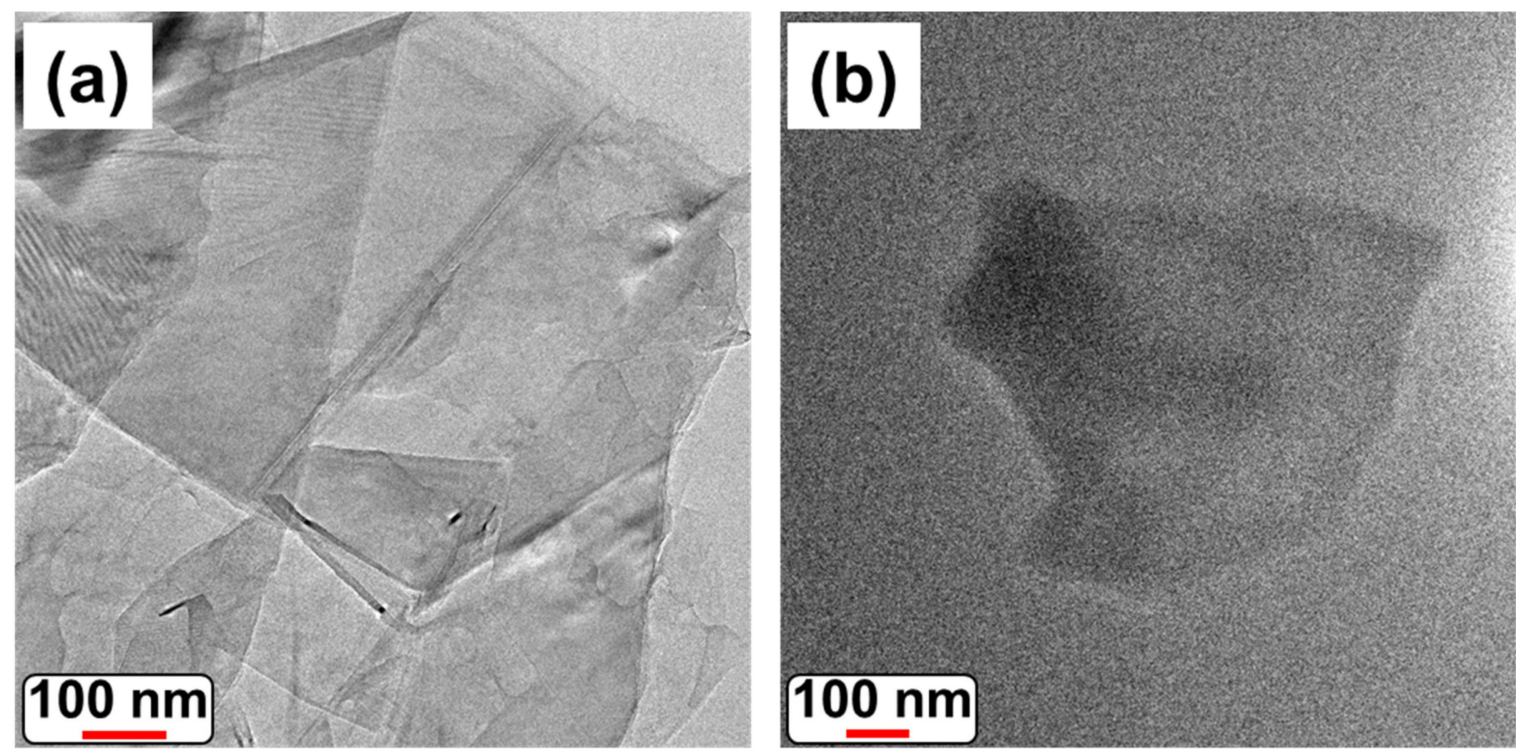

Figure 3. (a,b) HRTEM images of GPNVP composite. 
Attenuated total reflectance Fourier transform infrared (ATR-FTIR) spectra of GP and GPNVP composite are presented in Figure 4a. The absorption spectra of GP and GPNVP composite divulge the differences between them. The band around $1700 \mathrm{~cm}^{-1}$ in GPNVP composite is ascribed to the $\mathrm{C}=\mathrm{O}$ stretching [41,42], which is not observed in GP. The presence of a weak absorption band around $1600 \mathrm{~cm}^{-1}$ in GP and GPNVP composite confirms the presence of $\mathrm{sp}^{2} \mathrm{C}=\mathrm{C}$ stretching of the graphene sheet. This further agrees with the bands around $860 \mathrm{~cm}^{-1}$ in both GP and GPNVP composite which are indicative of the out-of-plane bending of the $\mathrm{C}-\mathrm{H}$ bond from the graphene sheet. The existence of a band around $1400 \mathrm{~cm}^{-1}$ reveals the C-N stretching in the GPNVP composite that is absent in GP. The adsorption band around $1200 \mathrm{~cm}^{-1}$ might be attributed to the $\mathrm{C}-\mathrm{C}$ stretching of the polymer backbone. The presence of $\mathrm{C}=\mathrm{O}$ and $\mathrm{C}-\mathrm{N}$ stretching from PNVP polymer in the GPNVP composite confirms the successful formation of the GPNVP composite. The Raman spectra for the GP and GPNVP composite in Figure $4 \mathrm{~b}$ show three characteristic peaks. GP shows the D band around $1347 \mathrm{~cm}^{-1}, \mathrm{G}$ band around $1582 \mathrm{~cm}^{-1}$, and 2D band at $2718 \mathrm{~cm}^{-1}$. Meanwhile, the GPNVP composite shows the $\mathrm{D}$ band around $1342 \mathrm{~cm}^{-1}, \mathrm{G}$ band at $1575 \mathrm{~cm}^{-1}$, [43], and 2D band at $2706 \mathrm{~cm}^{-1}$. The small $\mathrm{D}$ bands in GP and GPNVP composite indicate low or fewer defects. The D band originates from transverse optical phonons around the Brillouin zone corner $K$, breathing modes of the benzene ring in graphene sheets [44]. The first-order Raman scattering by in-plane transverse and longitudinal phonons, which are doubly generated by in-plane vibration modes, are responsible for the $\mathrm{G}$ band. Second-order Raman scattering by inplane transverse optical phonons near the boundary of the Brillouin zone is responsible for the 2D band [45]. Additionally, a small peak around $2440 \mathrm{~cm}^{-1}$ for GP and GPNVP composite is assigned as $\mathrm{D}+\mathrm{D}^{\prime \prime}$, which is the combination of $\mathrm{D}$ phonon and an acoustic longitudinal phonon $\mathrm{D}^{\prime \prime}$. D, G, and 2D bands of the GPNVP composite show a slight shift to a lower wavenumber compared to $2 \mathrm{D}$ band values of GP. This suggests the exfoliation of graphite into few-layered graphene sheets [46]. The $\mathrm{I}_{\mathrm{D}} / \mathrm{I}_{\mathrm{G}}$ values correspond to the defect level of composites $[47,48]$. The $\mathrm{I}_{\mathrm{D}} / \mathrm{I}_{\mathrm{G}}$ value of GP was calculated as 0.033 , while the $\mathrm{I}_{\mathrm{D}} / \mathrm{I}_{\mathrm{G}}$ value of the GPNVP composite was calculated as 0.036 . The slight increase of $\mathrm{I}_{\mathrm{D}} / \mathrm{I}_{G}$ values from GP to GPNVP composite suggests that the presence of PNVP on graphene surface is responsible for the slight defects of graphene sheets.
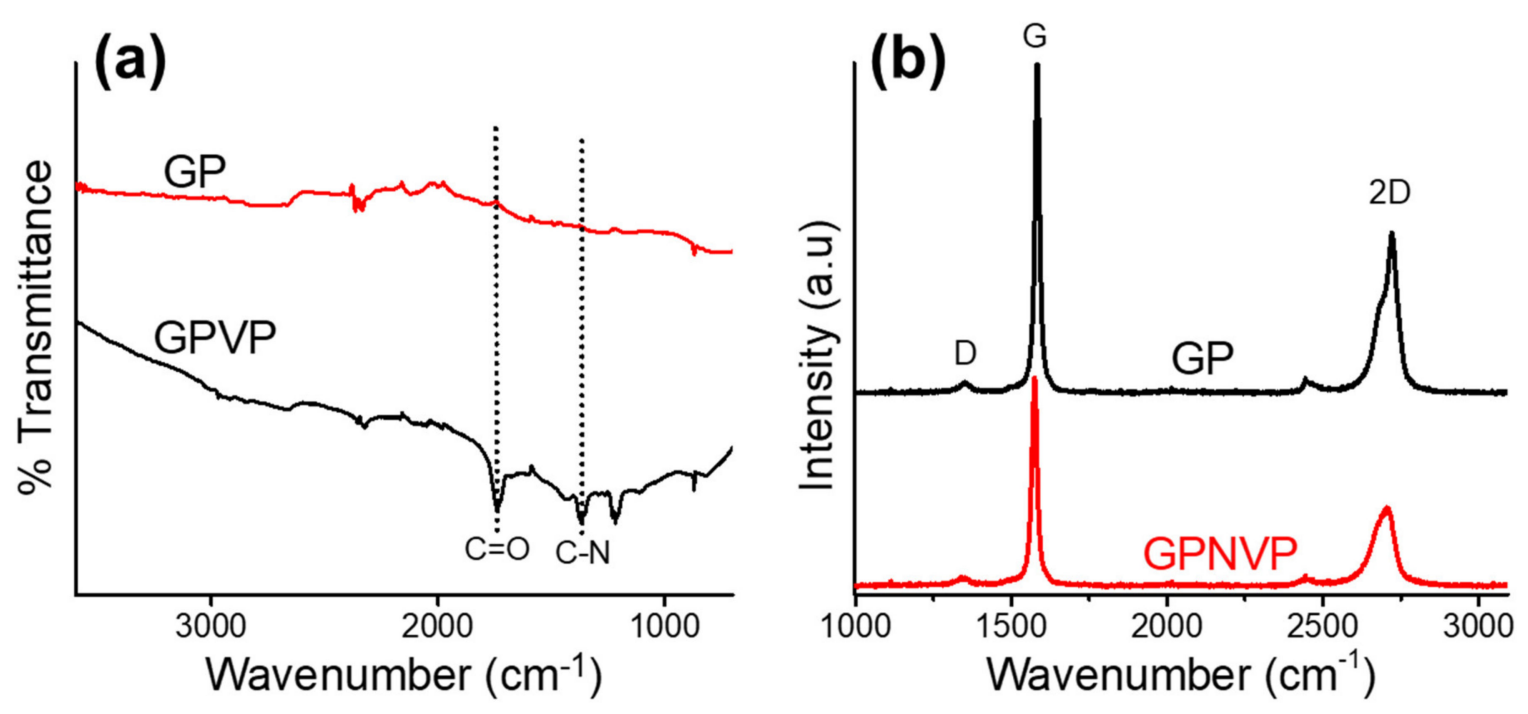

Figure 4. (a) Comparison of ATR-FTIR and (b) Raman spectra of graphite powder (GP) and GPNVP composite.

GP and GPNVP composite were further characterized using X-ray photoelectron spectroscopy (XPS) to investigate the elemental compositions of GP and GPNVP composite. Figure 5a, a survey spectrum, shows the existence of atoms such as $\mathrm{O}$ and $\mathrm{C}$ in GP and 
$\mathrm{O}, \mathrm{C}$, and $\mathrm{N}$ atoms in the GPNVP composite. An additional nitrogen atom in the GPNVP composite is ascribed to the PNVP polymer. Figure $5 b, c$ shows the high-resolution $C 1 s$ spectra of GP and GPNVP composite, respectively. The C 1s spectrum of GP shows four peaks at $284.77,285.45,286.10$, and $286.82 \mathrm{eV}$ that correspond to $\mathrm{C}=\mathrm{C}, \mathrm{C}-\mathrm{C}, \mathrm{C}-\mathrm{O}$, and $\mathrm{C}=\mathrm{O}$, respectively [49]. The $\mathrm{C} 1 \mathrm{~s}$ spectrum of the GPNVP composite (Figure $5 \mathrm{c}$ ) shows five peaks at 284.74, 285.43, 286.06, 286.68, and $287.45 \mathrm{eV}$ that correspond to $\mathrm{C}=\mathrm{C}, \mathrm{C}-\mathrm{C} / \mathrm{C}-\mathrm{N}$, $\mathrm{C}-\mathrm{O}, \mathrm{C}=\mathrm{O}$, and $\mathrm{N}-\mathrm{C}=\mathrm{O} / \mathrm{HO}-\mathrm{C}=\mathrm{O}$, respectively $[50,51]$. A peak around 287.43, which corresponds to $\mathrm{N}-\mathrm{C}=\mathrm{O}$, originates from $\mathrm{PNVP}$ polymer. The high-resolution spectrum (Figure 5d,e) of the $\mathrm{O}$ 1s level of GP was deconvoluted into two peaks, and the GPNVP composite was deconvoluted into three peaks. Two peaks of GP at 532.45 and $533.79 \mathrm{eV}$ correspond to $\mathrm{C}=\mathrm{O}$ and $\mathrm{O}=\mathrm{C}-\mathrm{OH}$, respectively [50,52-54]. Three peaks of the GPNVP composite at 531.96, 533.08, and 534.14 eV are attributed to $\mathrm{C}=\mathrm{O}, \mathrm{O}=\mathrm{C}-\mathrm{OH}$, and $\mathrm{H}-\mathrm{O}-\mathrm{H}$, respectively. The presence of $\mathrm{H}-\mathrm{O}-\mathrm{H}$ (water molecules) in GPNVP composite suggests the hydrophilicity of graphene surfaces in GPNVP composite, unlike the hydrophobic GP. The peak at $531.96 \mathrm{eV}$ can be indexed for the repeated unit of NVP on the graphene surface. The survey spectrum of GP confirms the absence of the $\mathrm{N}$ atom. The $\mathrm{N}$ 1s peak of the GPNVP composite (Figure 5f) split into two components with binding energies at 400.26 and $401.68 \mathrm{eV}$. These peaks can be assigned to $\mathrm{C}-\mathrm{N}$ and positively charged $\mathrm{N}\left(\mathrm{C}-\mathrm{N}^{+}\right)$ species, respectively [55]. The $\mathrm{O} 1 \mathrm{~s}$ level confirms repeated units of NVP on the graphene surface, and the $\mathrm{N}$ 1s energy level confirms the presence of $\mathrm{C}-\mathrm{N}$ and $\mathrm{C}-\mathrm{N}^{+}$species in the GPNVP composite. These results confirm the successful formation of the GPNVP composite. Moreover, the relative atomic ratios of $\mathrm{C}$ and $\mathrm{O}$ in GP and GPNVP composite were calculated as 39.83 and 16.87, respectively. The decrease of C/O ratio in the GPNVP composite when compared to that in GP indicates the successful functionalization of PNVP on the GP surface in the GPNVP composite.

Figure 6a represents the X-ray diffraction (XRD) patterns of GP and GPNVP composite. The three major characteristic peaks of GP, (002) at $26.65^{\circ},(101)$ at $44.6^{\circ}$, and $(004)$ at $54.79^{\circ}$, are evident from Figure 6a [56,57]. The GPNVP composite displays three peaks: (002) at $26.54^{\circ},(101)$ at $44.58^{\circ}$, and (004) at $54.64^{\circ}$. The GPNVP composite reveals a slight shift in the peaks, broadened diffraction peaks, and a dramatic decrease in the intensities compared to GP. These changes and shifts in peaks suggest the exfoliation of graphene layers in GPNVP composite along with the functionalization of the graphene surface with PNVP [58]. Further, exfoliation is evident from the interlayer distance of the GPNVP composite, calculated as $0.336 \mathrm{~nm}$, which is larger than GP $(0.334 \mathrm{~nm})$ [59]. The slight increase in the interlayer distance of the GPNVP composite reveals that the in situ polymerization of NVP monomers on graphene surfaces helps the complete or partial exfoliation of graphite into graphene layers. Figure $6 \mathrm{~b}$ shows the thermogravimetric analysis (TGA) curves of GP and GPNVP composite. For GP, a slight weight loss above $100{ }^{\circ} \mathrm{C}$, which corresponds to the evaporation of water/moisture, is observed. After this, no significant weight loss is observed, leaving behind about $97 \%$ mass. The GPNVP composite reveals a weight loss above $100{ }^{\circ} \mathrm{C}$ which contributes to adsorbed moisture or water molecules in the GPNVP composite. The degradation of PNVP starts at a temperature of $\sim 350{ }^{\circ} \mathrm{C}$ and proceeds up to $420{ }^{\circ} \mathrm{C}$ with weight loss of $84 \%$ [60]. In the final step, above 420 to $570{ }^{\circ} \mathrm{C}$, the complete degradation of PVP takes place with weight loss of $83 \%$, leaving around $80 \%$ of the carbon residue $[61,62]$. From this TGA measurement, the amount of PNVP functionalized on graphene surfaces in GPNVP composite is calculated to be approximately $15 \%$. To check the reproducibility of the GPNVP composite, the composite was prepared by adopting the same procedure. Sizes of the graphene sheets in the GPNVP composite were in the error range, and the TGA analysis showed $\sim 15 \%$ of PNVP in the GPNVP composite. These measurements confirm the reproducibility of the GPNVP composite. This further supports the functionalization of graphene surfaces with PNVP polymer, the successful formation of the GPNVP composite, and shows good agreement with other results obtained from FESEM, HRTEM, FTIR, Raman, and XPS studies. Further, to explore the dispersion stabilities, photographic images were taken at different time intervals (Figure S4): immediately after the preparation of 
dispersion, after $1 \mathrm{~h}$, and after 1 month. These figures reveal the stable GPNVP dispersion lasts for at least a month. Significant differences were not observed between the pictures. All analyses confirm the successful formation of the GPNVP composite and the existence of heteroatoms such as $\mathrm{C}, \mathrm{O}$, and N. Scheme 1 reveals the interaction between PNVP and graphene surfaces in a GPNVP composite. The stable dispersion is attributed to the interaction of nitrogen atoms from PNVP [34,36]. Additionally, oxygen atoms in PNVP might be involved in the interaction with graphene surfaces and results in stable dispersion for a long time. The existence of heteroatoms and their involvement in the interaction with graphene surfaces is suggested for electrochemical studies.

(a)
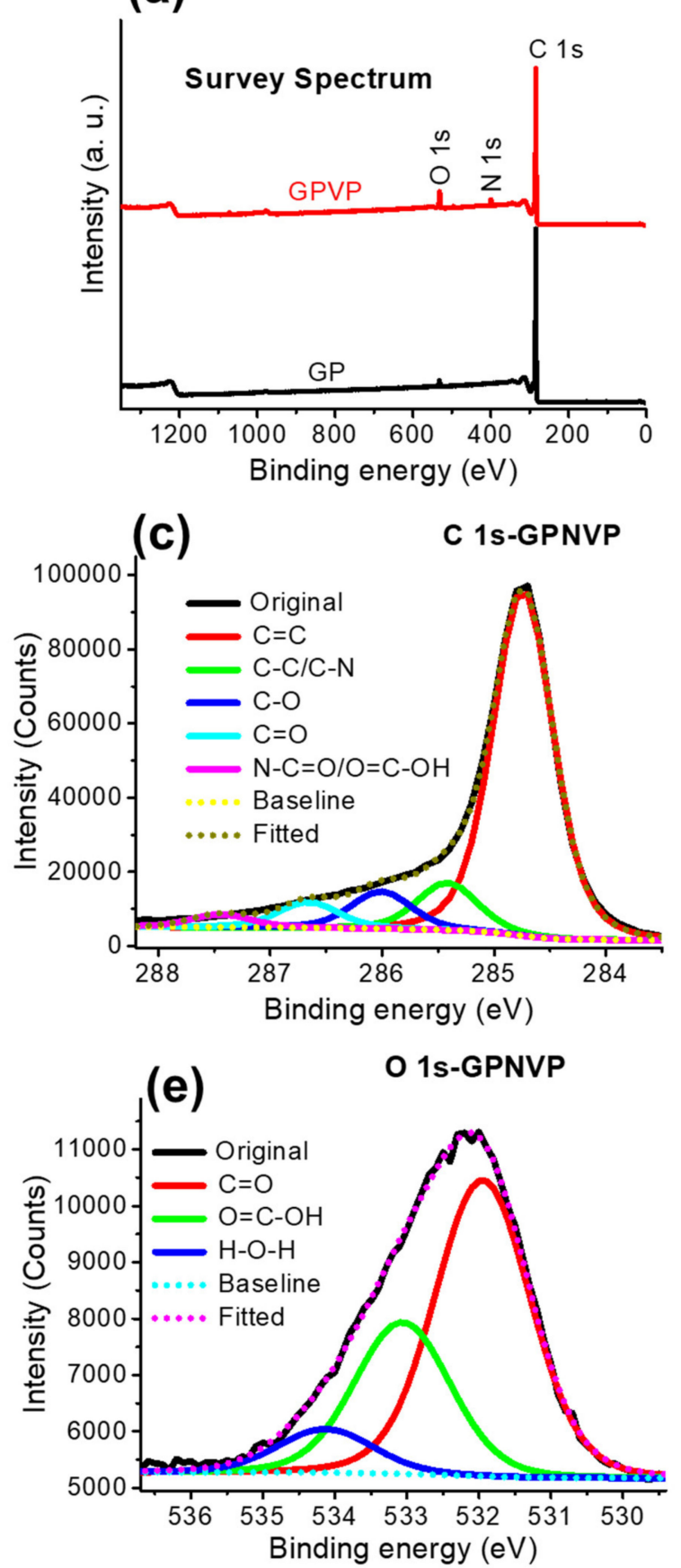
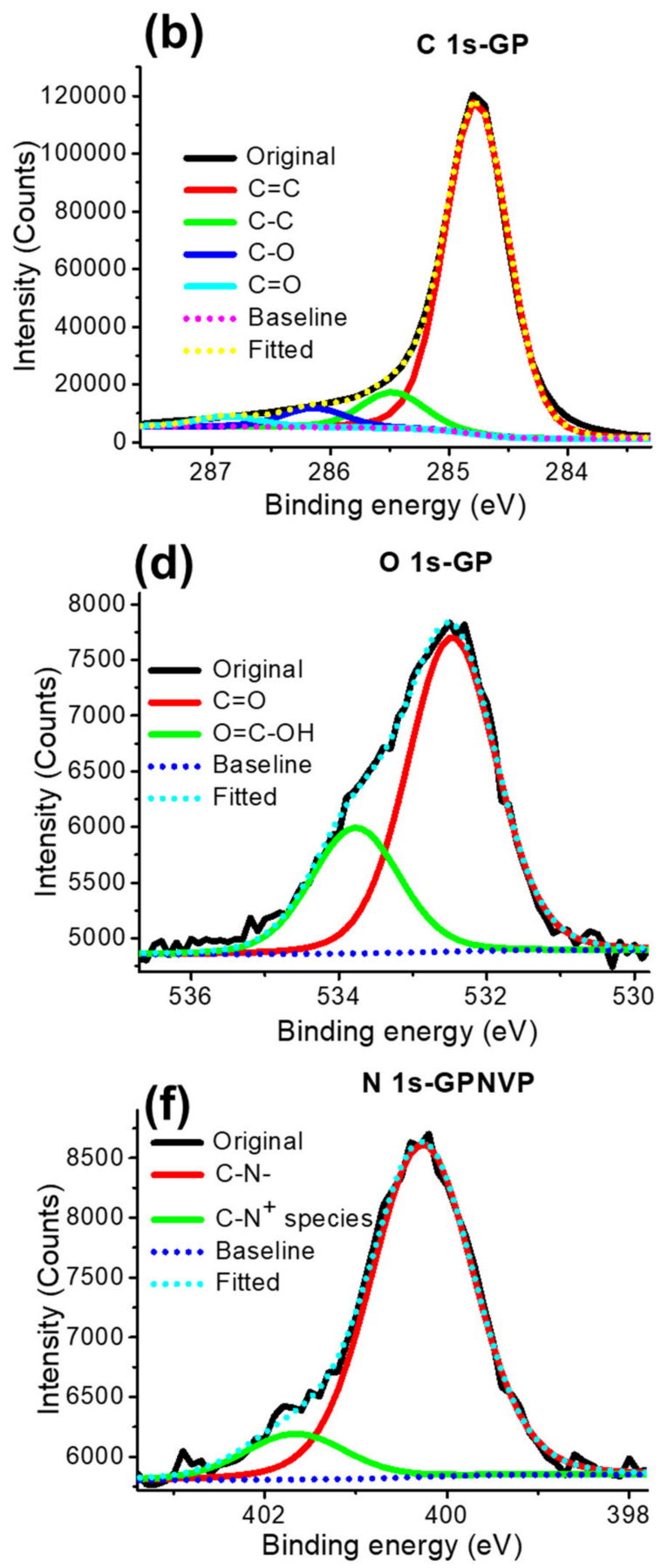

Figure 5. (a) XPS survey spectra of GP and GPNVP composite, (b) C 1s spectrum of GP, (c) C 1s spectrum of GPNVP composite, (d) O 1s spectrum of GP, (e) O 1s spectrum of GPNVP composite, and (f) N 1s spectrum of GPNVP composite. 

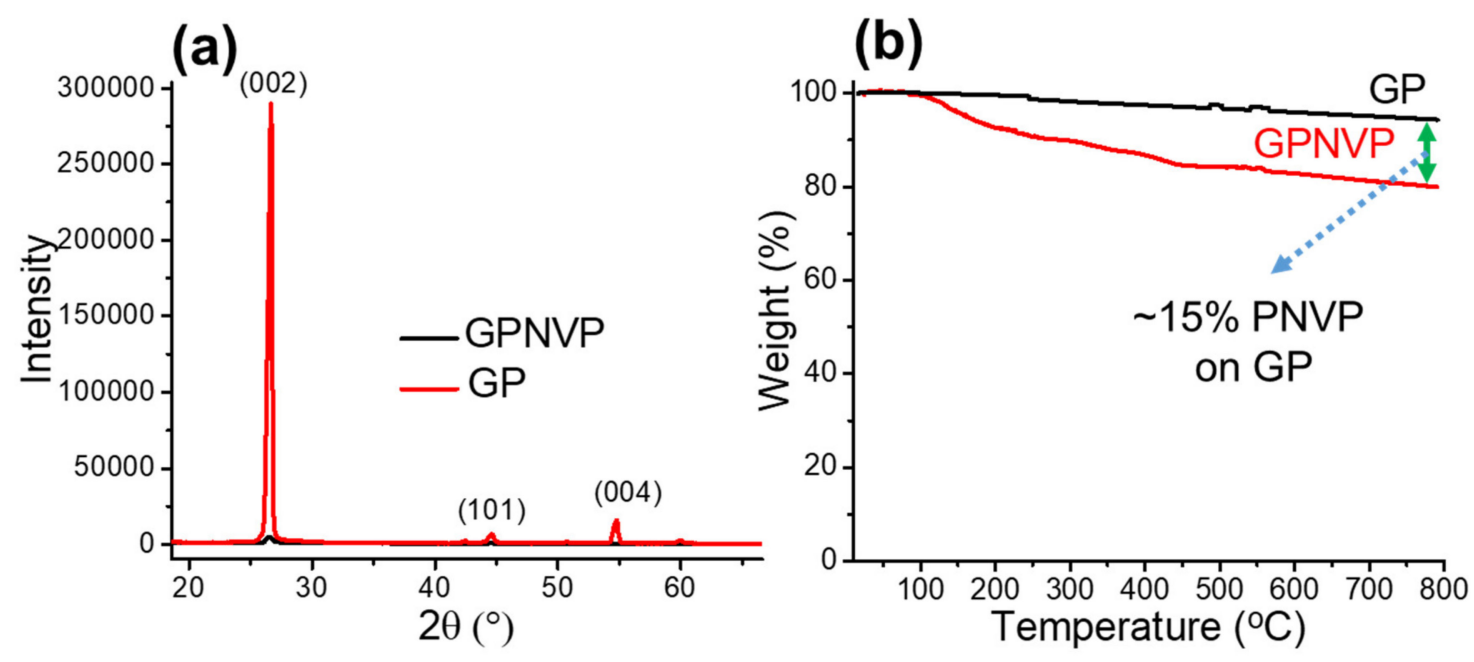

Figure 6. (a) XRD patterns and (b) TGA curves of GP and GPNVP composite under $\mathrm{N}_{2}$ atmosphere.

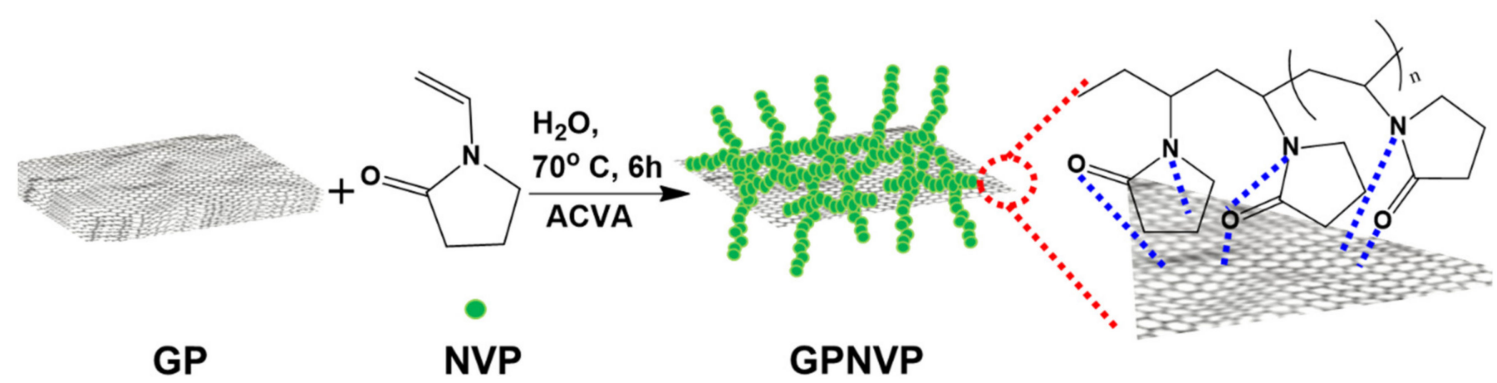

Scheme 1. Preparation of graphene surface functionalized by poly- $N$-vinyl-2-pyrrolidone using in situ polymerization.

Finally, the cyclic voltammetry (CV) measurement of the GPNVP composite was performed in the typical three-electrode system in an acidic environment to analyze the electrochemical behavior of the resulting GPNVP composite. Figure 7 displays the CV curves of the GPNVP composite at different scan rates of 5, 10, 25, 50, 75, 100,150, 200, 250, 300,400 , and $500 \mathrm{mV} / \mathrm{s}$ within the potential range from 0.0 to $0.6 \mathrm{~V}$ (vs. $\mathrm{Hg} / \mathrm{Hg}_{2} \mathrm{SO}_{4}$ ) in an aqueous $1 \mathrm{M} \mathrm{H}_{2} \mathrm{SO}_{4}$ electrolyte. The $\mathrm{CV}$ loops of the GPNVP composite show a typical rectangular shape of carbon material without obvious oxygen and hydrogen evolution peaks at all scan rates, indicating the ideal electric double-layer capacitive behavior and good charge propagation within the GPNVP electrode [63-65]. The GPNVP electrode displays the obvious increments in the current with an increase in the scan rates from 5 to $500 \mathrm{mV} / \mathrm{s}$. This suggests a good rate capability and good ion transport in the GPNVP electrode [66]. Moreover, it is interesting to note that the GPNVP electrode still maintains a nearly rectangular CV shape even at $500 \mathrm{mV} / \mathrm{s}$. This result suggests that the GPNVP composite has excellent rate capability with the capacitive property. Besides, the $\mathrm{CV}$ measurement of the GPNVP composite was performed at a scan rate of $50 \mathrm{mV} / \mathrm{s}$ up to 1000 cycles and the corresponding results are shown in Figure S5. The shape and area of the CV curves are comparable even after 1000 cycles (Figure S5), which demonstrates the good rate capability and good electrochemical resistance of the GPNVP composite after many cycles [67]. Moreover, these results suggest that the resulting GPNVP composite electrode could be ideal for various electrochemical applications. 

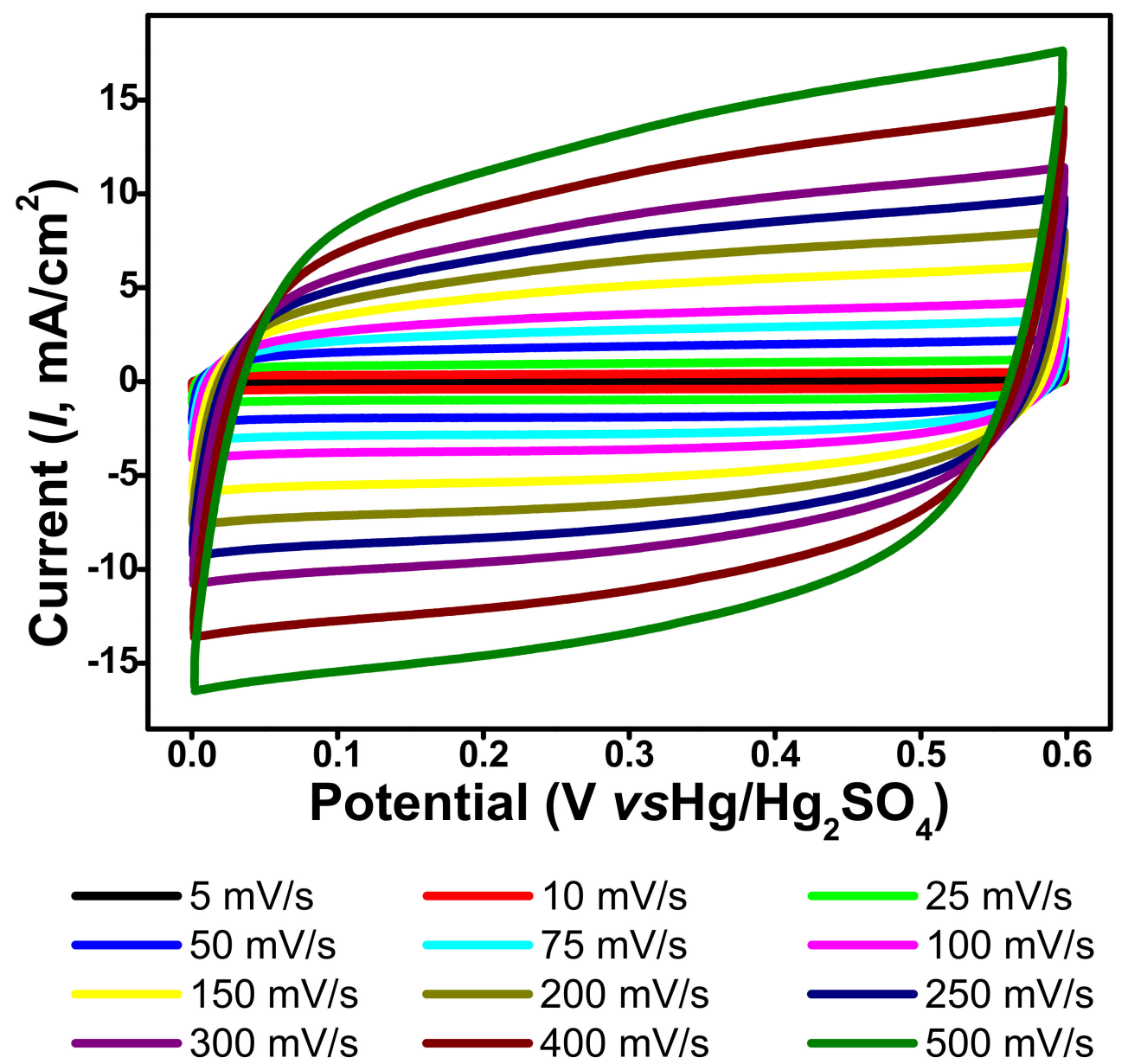

Figure 7. Cyclic voltammograms of GPNVP composite at various scan rates $(5-500 \mathrm{mV} / \mathrm{s})$ within the potential range from 0.0 to $0.6 \mathrm{~V}$ (vs. $\mathrm{Hg} / \mathrm{Hg}_{2} \mathrm{SO}_{4}$ ) in an aqueous $1 \mathrm{M} \mathrm{H}_{2} \mathrm{SO}_{4}$ electrolyte.

Figure S6 shows the electrochemical impedance spectroscopy (EIS) plot of the GPNVP composite electrode in an aqueous $1 \mathrm{M} \mathrm{H}_{2} \mathrm{SO}_{4}$ electrolyte at room temperature. The EIS Nyquist plot of the GPNVP electrode shows lower solution resistance $\left(2.7 \Omega / \mathrm{cm}^{2}\right)$. The smaller distorted semicircle ( $\mathrm{arc}$ ) in the high-frequency region (inset of Figure S6) is due to the double-layer capacitance and charge transfer resistance [68]. The straight line parallel to the $y$-axis with a tilt toward the $x$-axis, observed in the low-frequency regions, is attributed to ion transport through the GPNVP electrode. Moreover, the EIS reveals the high-capacitance behaviors of the GPNVP electrode because of the porous structure of the GPNVP composite. Therefore, the prepared GPNVP composite could be unique for high-powered supercapacitor applications.

\section{Summary and Conclusions}

In this work, we have stabilized graphene surfaces with PNVP and exfoliated graphite to few-layered graphene by in situ polymerization of NVP. The prepared GPNVP composite was characterized well by various analyses, and the results were compared to GP. Surface and elemental mapping by FESEM reveals the uniform distribution of PNVP over the graphene surface, and thin layers of graphene sheets were confirmed from FESEM and HRTEM analyses. ATR-FTIR and XPS revealed the presence of PNVP on the graphene surface in the GPNVP composite. XRD and Raman studies of GPNVP suggest the partial exfoliation of graphite into graphene sheets. Thus, all the physicochemical techniques confirm the successful formation of GPNVP and functionalization of PNVP on the graphene surface. Further TGA confirmed the existence of $15 \%$ of PNVP in the GPNVP composite. 
Besides, the electrochemical performance of the prepared GPNVP composite as an electrode material was investigated by $\mathrm{CV}$ measurements within the potential range from 0.0 to $0.6 \mathrm{~V}$ (vs. $\mathrm{Hg} / \mathrm{Hg}_{2} \mathrm{SO}_{4}$ ) and EIS study in an aqueous $1 \mathrm{M} \mathrm{H}_{2} \mathrm{SO}_{4}$ electrolyte. The fabricated GPNVP composite electrode exhibited good rate capability and reversibility at a high scan rate of $500 \mathrm{mV} / \mathrm{s}$. Moreover, it is interesting to note that the GPNVP electrode possesses long cycle life and maintains a nearly rectangular CV shape even after 1000 cycles. The aforesaid results suggest that the prepared GPNVP composite is suitable for practical applications, including in various electrochemical fields. The present study has a limitation towards the determination of the molecular weight of polymers that functionalized on the graphene surface, which will be considered in the future. However, this report will focus attention on the preparation of a stable graphene composite in a facile way and directs for the usage of composites in different applications.

\section{Materials and Methods}

\subsection{Materials}

GP and 4,4'-azobis(4-cyanovaleric acid) (ACVA, $\geq 98.0 \%$ ) were obtained from SigmaAldrich and used as received. NVP $\geq 99 \%$ contains sodium hydroxide as an inhibitor. $\mathrm{N}$-Methyl-2-pyrrolidone (NMP, 99\%), polyvinylidene fluoride (PVDF, MQ100), and sulfuric acid $\left(\mathrm{H}_{2} \mathrm{SO}_{4}, 95 \%\right)$ were purchased from Sigma-Aldrich. Distilled and deionized (DI) water was used in all experiments. In situ polymerization of the NVP monomer on GP was carried out using a bath sonicator ( $40 \mathrm{kHz}, 110 \mathrm{~W}$, BRANSON 3800, CT, USA). Bare carbon cloth (CC) was purchased from FuelCellsEtc (College Station, TX, USA) and used for electrochemical studies.

\subsection{Preparation of Graphene Dispersion by In Situ Polymerization of NVP on GP Surface}

The GP surface was stabilized with PNVP by the in situ polymerization of NVP monomer, as shown in Scheme 1. For this, $350 \mathrm{mg}$ ( $3.14 \mathrm{mmol}$ ) of NVP monomer and $44.1 \mathrm{mg}(0.15 \mathrm{mmol})$ of ACVA as an initiator were placed in a $70 \mathrm{~mL}$ glass vial. To this, $175 \mathrm{mg}$ GP and $70 \mathrm{~mL}$ of degassed DI water were added and purged with nitrogen for $30 \mathrm{~min}$. After $30 \mathrm{~min}$, the glass vial was sealed carefully and sonicated in a bath sonicator. The mixture was sonicated and the bath temperature was maintained at $70{ }^{\circ} \mathrm{C}$, for the polymerization of NVP, for $7 \mathrm{~h}$. Subsequently, the GPNVP dispersion was centrifuged (VS-18000M, VISION Scientific Co. Ltd., Yuseong-Gu, South Korea) for 15 min at $5000 \mathrm{rpm}$. The unreacted monomers and free polymers were washed out from the prepared GPNVP composite by centrifugation. The supernatant layer was decanted and dried for further use.

\subsection{Characterization Methods}

Pristine GP and GPNVP composite were characterized using various physicochemical techniques. ATR-FTIR spectra were recorded in transmittance mode on a Perkin Elmer Spectrum Two in the wavenumber range from 700 to $3700 \mathrm{~cm}^{-1}$. ATR-FTIR was used to evaluate the chemical compositions and to confirm the formation of GPNVP. The Raman spectrum was recorded on an XploRA Micro-Raman spectrophotometer (Horiba, Palaiseau, France) with a range between 1000 and $3200 \mathrm{~cm}^{-1}$ at the Core Research Support Center for Natural Products and Medical Materials of Yeungnam University. FESEM with EDS was used to evaluate the surface morphology of the composites. FESEM with EDS measurements were carried out using Hitachi S- 4800 equipped with EDX at an accelerating voltage of $10 \mathrm{kV}$. Further, the morphologies were confirmed from HRTEM images that were obtained from Tecnai G2 F20 S-TWIN with an operating accelerating voltage of $120 \mathrm{kV}$. The XPS spectra were recorded using a K-Alpha (Thermo Scientific, Seoul, South Korea). CasaXPS software was used for the deconvolution of the high-resolution XPS spectra. XRD studies were carried out using a PANalytical $X^{\prime} \mathrm{Pert}^{3} \mathrm{MRD}$ diffractometer with monochromatized $\mathrm{Cu} \mathrm{K} \alpha$ radiation $(\lambda=1.54 \AA)$ at $40 \mathrm{kV}$ and $30 \mathrm{~mA}$ and were recorded in the range from 10 to $70^{\circ}(2 \theta)$. TGA measurement was carried out on an SDT Q600 with nitrogen atmosphere over 20 (room temperature) to $800{ }^{\circ} \mathrm{C}$ with $10^{\circ} \mathrm{C} / \mathrm{min}$. 


\subsection{Fabrication of Working Electrode and Cyclic Voltammetry Measurements}

The prepared GPNVP composite was used for the fabrication of the working electrode. To fabricate the working electrode, GPNVP composite and PVDF in the ratio 95:5 were ground well in an appropriate amount of NMP to make a homogeneous paste. The resulting homogeneous paste was coated on the conducting CC with an area of $1 \mathrm{~cm}^{2}$ by the dropcasting method, after which the electrode was kept at $100{ }^{\circ} \mathrm{C}$ in a hot-air oven for $48 \mathrm{~h}$ to dry the electrode. After fabrication, the modified working electrode (GPNVP/CC) was examined using $\mathrm{CV}$ in a typical three-electrode system. The CV studies were performed on a CorrTest-CS350 electrochemical workstation in an aqueous $1 \mathrm{M} \mathrm{H}_{2} \mathrm{SO}_{4}$ electrolyte. A commercial $\mathrm{Hg} / \mathrm{Hg}_{2} \mathrm{SO}_{4}\left(\mathrm{Sat} . \mathrm{K}_{2} \mathrm{SO}_{4}\right.$ ) electrode was employed as a reference electrode and a platinum plate $\left(1 \mathrm{~cm}^{2}\right)$ was used as a counter electrode. The $\mathrm{CV}$ measurements were carried out within the potential ranges between 0.0 and $0.6 \mathrm{~V}$ at the different scan rates of $5,10,25,50,75,100,150,200,250,300,400$, and $500 \mathrm{mV} / \mathrm{s}$. EIS measurements were performed in the frequency range of $0.01-100 \mathrm{kHz}$ with an alternating current amplitude of $5 \mathrm{mV}$. The electrochemical test was conducted at room temperature.

Supplementary Materials: The following are available online, Figure S1: FESEM images of GP surfaces at different magnifications and its EDS spectrum, Figure S2: (a) FESEM image of GP surface and their corresponding elemental mapping (b) carbon and (c) oxygen, Figure S3: HRTEM images of GP with different magnifications, Figure S4: Photographic images of GPNVP composite dispersions at different time intervals, immediately, after $1 \mathrm{~h}$ and 1 month, Figure S5: Cycling performance of GPNVP electrode (before and after $1000 \mathrm{CV}$ cycles) at a scan rate of $50 \mathrm{mV} / \mathrm{s}$, and Figure S6: Electrochemical impedance spectrum (EIS) of GPNVP electrode (inset: magnification of EIS) in an aqueous $1 \mathrm{M} \mathrm{H}_{2} \mathrm{SO}_{4}$ electrolyte at room temperature.

Author Contributions: Conceptualization and writing-original draft preparation, S.P.; formal analysis and investigation, R.A.; writing-review and editing, T.N.J.I.E.; funding acquisition, J.-J.S.; supervision and project administration, Y.R.L. All authors have read and agreed to the published version of the manuscript.

Funding: This research was supported by Basic Science Research Program through the National Research Foundation of Korea (NRF) funded by the Ministry of Education (2014R1A6A1031189). This research was also partially supported by the National Research Foundation (NRF) of Korea funded by the Ministry of Education, Science, and Technology (2012M3A7B4049677).

Data Availability Statement: The data presented in this study are available on request from the corresponding author.

Conflicts of Interest: The authors declare no conflict of interest.

Sample Availability: Samples of GPNVP composite is available from the authors.

\section{References}

1. Geim, A.K.; Novoselov, K.S. The rise of graphene. Nat. Mater. 2007, 6, 183-191. [CrossRef] [PubMed]

2. Novoselov, K.S.; Geim, A.K.; Morozov, S.V.; Jiang, D.; Zhang, Y.; Dubonos, S.V.; Grigorieva, I.V.; Firsov, A.A. Electric Field Effect in Atomically Thin Carbon Films. Science 2004, 306, 666-669. [CrossRef] [PubMed]

3. Elmarakbi, A.; Azoti, W. Chapter 1: State of the Art on Graphene Lightweighting Nanocomposites for Automotive Applications. In Experimental Characterization, Predictive Mechanical and Thermal Modeling of Nanostructures and their Polymer Composites; Marotti de Sciarra, F., Russo, P., Eds.; Elsevier: Amsterdam, The Netherlands, 2018; pp. 1-23.

4. Sahoo, S. Graphene in the Domain of Construction: A Review of Applications and Prospects. In Sustainable Construction and Building Materials; Das, B.B., Neithalath, N., Eds.; Springer: Singapore, 2019; pp. 325-334.

5. Ruhl, G.; Wittmann, S.; Koenig, M.; Neumaier, D. The integration of graphene into microelectronic devices. Beilstein J. Nanotechnol. 2017, 8, 1056-1064. [CrossRef]

6. Vlasov, A.I.; Terent'ev, D.S.; Shakhnov, V.A. Graphene flexible touchscreen with integrated analog-digital converter. Russ. Microelectron. 2017, 46, 192-199. [CrossRef]

7. Olabi, A.; Abdelkareem, M.A.; Wilberforce, T.; Sayed, E.T. Application of graphene in energy storage device-A review. Renew. Sustain. Energy Rev. 2021, 135, 110026. [CrossRef]

8. Atchudan, R.; Edison, T.N.J.I.; Perumal, S.; Vinodh, R.; Muthuchamy, N.; Lee, Y.R. One-pot synthesis of Fe3O4@graphite sheets as electrocatalyst for water electrolysis. Fuel 2020, 277, 118235. [CrossRef] 
9. Atchudan, R.; Edison, T.N.J.I.; Perumal, S.; Thirukumaran, P.; Vinodh, R.; Lee, Y.R. Green synthesis of nitrogen-doped carbon nanograss for supercapacitors. J. Taiwan Inst. Chem. Eng. 2019, 102, 475-486. [CrossRef]

10. Ollik, K.; Lieder, M. Review of the Application of Graphene-Based Coatings as Anticorrosion Layers. Coatings 2020, $10,883$. [CrossRef]

11. Nag, A.; Mitra, A.; Mukhopadhyay, S.C. Graphene and its sensor-based applications: A review. Sens. Actuators A Phys. 2018, 270, 177-194. [CrossRef]

12. Atchudan, R.; Muthuchamy, N.; Edison, T.N.J.I.; Perumal, S.; Vinodh, R.; Park, K.H.; Lee, Y.R. An ultrasensitive photoelectrochemical biosensor for glucose based on bio-derived nitrogen-doped carbon sheets wrapped titanium dioxide nanoparticles. Biosens. Bioelectron. 2019, 126, 160-169. [CrossRef] [PubMed]

13. Alammar, A.; Park, S.-H.; Williams, C.J.; Derby, B.; Szekely, G. Oil-in-water separation with graphene-based nanocomposite membranes for produced water treatment. J. Membr. Sci. 2020, 603, 118007. [CrossRef]

14. Liu, J.; Zhu, Y.; Wang, C.; Singh, T.; Wang, N.; Liu, Q.; Cui, Z.; Ma, L. Facile synthesis of controllable graphene-co-shelled reusable $\mathrm{Ni} / \mathrm{NiO}$ nanoparticles and their application in the synthesis of amines under mild conditions. Green Chem. 2020, 22, 7387-7397. [CrossRef]

15. Alammar, A.; Park, S.-H.; Ibrahim, I.; Arun, D.; Holtzl, T.; Dumée, L.F.; Lim, H.N.; Szekely, G. Architecting neonicotinoidscavenging nanocomposite hydrogels for environmental remediation. Appl. Mater. Today 2020, 21, 100878. [CrossRef]

16. Abdu, H.I.; Eid, K.; Abdullah, A.M.; Sliem, M.H.; Elzatahry, A.; Lu, X. Dry ice-mediated rational synthesis of edge-carboxylated crumpled graphene nanosheets for selective and prompt hydrolysis of cellulose and eucalyptus lignocellulose under ambient reaction conditions. Green Chem. 2020, 22, 5437-5446. [CrossRef]

17. Geim, A.K.; MacDonald, A.H. Graphene: Exploring carbon flatland. Phys. Today 2007, 60, 35-41.

18. Chiu, P.L.; Mastrogiovanni, D.D.T.; Wei, D.; Louis, C.; Jeong, M.; Yu, G.; Saad, P.; Flach, C.R.; Mendelsohn, R.; Garfunkel, E.; et al. Microwave- and Nitronium Ion-Enabled Rapid and Direct Production of Highly Conductive Low-Oxygen Graphene. J. Am. Chem. Soc. 2012, 134, 5850-5856. [CrossRef]

19. Choucair, M.; Thordarson, P.; Stride, J.A. Gram-scale production of graphene based on solvothermal synthesis and sonication. Nat. Nanotechnol. 2009, 4, 30-33. [CrossRef]

20. Bansal, T.; Durcan, C.A.; Jain, N.; Jacobs-Gedrim, R.B.; Xu, Y.; Yu, B. Synthesis of few-to-monolayer graphene on rutile titanium dioxide. Carbon 2013, 55, 168-175. [CrossRef]

21. Papadakis, R.; Li, H.; Bergman, J.; Lundstedt, A.; Jorner, K.; Ayub, R.; Haldar, S.; Jahn, B.O.; Denisova, A.; Zietz, B.; et al. Metal-free photochemical silylations and transfer hydrogenations of benzenoid hydrocarbons and graphene. Nat. Commun. 2016, 7, 12962. [CrossRef]

22. Kawai, S.; Krejčí, O.; Nishiuchi, T.; Sahara, K.; Kodama, T.; Pawlak, R.; Meyer, E.; Kubo, T.; Foster, A.S. Three-dimensional graphene nanoribbons as a framework for molecular assembly and local probe chemistry. Sci. Adv. 2020, 6, eaay8913. [CrossRef] [PubMed]

23. Hernandez, Y.; Nicolosi, V.; Lotya, M.; Blighe, F.M.; Sun, Z.; De, S.; McGovern, I.T.; Holland, B.; Byrne, M.; Gun'Ko, Y.K.; et al. High-yield production of graphene by liquid-phase exfoliation of graphite. Nat. Nanotechnol. 2008, 3, 563-568. [CrossRef]

24. Krishnamoorthy, K.; Kim, G.-S.; Kim, S.J. Graphene nanosheets: Ultrasound assisted synthesis and characterization. Ultrason. Sonochem. 2013, 20, 644-649. [CrossRef] [PubMed]

25. Gao, Y.; Shi, W.; Wang, W.; Wang, Y.; Zhao, Y.; Lei, Z.; Miao, R. Ultrasonic-Assisted Production of Graphene with High Yield in Supercritical $\mathrm{CO}_{2}$ and Its High Electrical Conductivity Film. Ind. Eng. Chem. Res. 2014, 53, 2839-2845. [CrossRef]

26. Ciesielski, A.; Samorì, P. Graphene via sonication assisted liquid-phase exfoliation. Chem. Soc. Rev. 2014, 43, 381-398. [CrossRef]

27. Aydin, F.; Chu, X.; Uppaladadium, G.; Devore, D.; Goyal, R.; Murthy, N.S.; Zhang, Z.; Kohn, J.; Dutt, M. Self-Assembly and Critical Aggregation Concentration Measurements of ABA Triblock Copolymers with Varying B Block Types: Model Development, Prediction, and Validation. J. Phys. Chem. B 2016, 120, 3666-3676. [CrossRef] [PubMed]

28. Coleman, J.N. Liquid Exfoliation of Defect-Free Graphene. Acc. Chem. Res. 2013, 46, 14-22. [CrossRef] [PubMed]

29. Baibarac, M.; Stingescu, L.; Stroe, M.; Negrila, C.; Matei, E.; Cotet, L.C.; Anghel, I.; Şofran, I.E.; Baia, L. Poly(Vinyl Chloride) Spheres Coated with Graphene Oxide Sheets: From Synthesis to Optical Properties and Their Applications as Flame-Retardant Agents. Polymers 2021, 13, 565. [CrossRef]

30. Nobile, M.R.; Raimondo, M.; Naddeo, C.; Guadagno, L. Rheological and Morphological Properties of Non-Covalently Functionalized Graphene-Based Structural Epoxy Resins with Intrinsic Electrical Conductivity and Thermal Stability. Nanomaterials 2020, 10, 1310. [CrossRef]

31. Rezvani Moghaddam, A.; Ranjbar, Z. Chapter 5-Dispersion and Dispersion Stability of Graphene in Aqueous Media for Waterborne Coating Application. In Handbook of Waterborne Coatings; Zarras, P., Soucek, M.D., Tiwari, A., Eds.; Elsevier: Amsterdam, The Netherlands, 2020; pp. 103-123.

32. Daniel, C.; Nagendra, B.; Acocella, M.R.; Cascone, E.; Guerra, G. Nanoporous Crystalline Composite Aerogels with Reduced Graphene Oxide. Molecules 2020, 25, 5241. [CrossRef]

33. Perumal, S.; Lee, H.M.; Cheong, I.W. High-concentration graphene dispersion stabilized by block copolymers in ethanol. J. Colloid Interface Sci. 2017, 497, 359-367. [CrossRef]

34. Perumal, S.; Park, K.T.; Lee, H.M.; Cheong, I.W. PVP-b-PEO block copolymers for stable aqueous and ethanolic graphene dispersions. J. Colloid Interface Sci. 2016, 464, 25-35. [CrossRef] [PubMed] 
35. Lee, H.M.; Perumal, S.; Cheong, I.W. Amphiphilic Fluorinated Block Copolymer Synthesized by RAFT Polymerization for Graphene Dispersions. Polymers 2016, 8, 101. [CrossRef] [PubMed]

36. Perumal, S.; Lee, H.M.; Cheong, I.W. A study of adhesion forces between vinyl monomers and graphene surfaces for non-covalent functionalization of graphene. Carbon 2016, 107, 74-76. [CrossRef]

37. Wajid, A.S.; Das, S.; Irin, F.; Ahmed, H.S.T.; Shelburne, J.L.; Parviz, D.; Fullerton, R.J.; Jankowski, A.F.; Hedden, R.C.; Green, M.J. Polymer-stabilized graphene dispersions at high concentrations in organic solvents for composite production. Carbon 2012, 50, 526-534. [CrossRef]

38. Ganguly, S.; Ghosh, S.; Das, P.; Das, T.K.; Ghosh, S.K.; Das, N.C. Poly(N-vinylpyrrolidone)-stabilized colloidal graphene-reinforced poly(ethylene-co-methyl acrylate) to mitigate electromagnetic radiation pollution. Polym. Bull. 2020, 77, 2923-2943. [CrossRef]

39. Chen, S.; Cheng, B.; Ding, C. Synthesis and Characterization of Poly(vinyl pyrrolidone)/Reduced Graphene Oxide Nanocomposite. J. Macromol. Sci. Part B 2015, 54, 481-491. [CrossRef]

40. Upadhyaya, S.; Gogoi, B.; Sarma, N.S. Poly(n-vinylpyrrolidone-co-acrylonitrile-co-methacrylic acid)_Graphene quantum dot conjugate: Synthesis and characterization for sensing ammonia vapour. J. Mater. Chem. C 2021, 9, 2165-2177. [CrossRef]

41. Song, Y.-J.; Wang, M.; Zhang, X.-Y.; Wu, J.-Y.; Zhang, T. Investigation on the role of the molecular weight of polyvinyl pyrrolidone in the shape control of high-yield silver nanospheres and nanowires. Nanoscale Res. Lett. 2014, 9, 17. [CrossRef]

42. Atchudan, R.; Edison, T.N.J.I.; Aseer, K.R.; Perumal, S.; Karthik, N.; Lee, Y.R. Highly fluorescent nitrogen-doped carbon dots derived from Phyllanthus acidus utilized as a fluorescent probe for label-free selective detection of Fe3+ ions, live cell imaging and fluorescent ink. Biosens. Bioelectron. 2018, 99, 303-311. [CrossRef]

43. Jo, W.-K.; Kumar, S.; Isaacs, M.A.; Lee, A.F.; Karthikeyan, S. Cobalt promoted TiO2/GO for the photocatalytic degradation of oxytetracycline and Congo Red. Appl. Catal. B Environ. 2017, 201, 159-168. [CrossRef]

44. Dresselhaus, M.S.; Jorio, A.; Filho, A.G.S.; Saito, R. Defect characterization in graphene and carbon nanotubes using Raman spectroscopy. Philos. Trans. R. Soc. A Math. Phys. Eng. Sci. 2010, 368, 5355-5377. [CrossRef]

45. Ferrari, A.C.; Meyer, J.C.; Scardaci, V.; Casiraghi, C.; Lazzeri, M.; Mauri, F.; Piscanec, S.; Jiang, D.; Novoselov, K.S.; Roth, S.; et al. Raman Spectrum of Graphene and Graphene Layers. Phys. Rev. Lett. 2006, 97, 187401. [CrossRef] [PubMed]

46. Skaltsas, T.; Karousis, N.; Yan, H.-J.; Wang, C.-R.; Pispas, S.; Tagmatarchis, N. Graphene exfoliation in organic solvents and switching solubility in aqueous media with the aid of amphiphilic block copolymers. J. Mater. Chem. 2012, 22, 21507-21512. [CrossRef]

47. Dai, J.; Peng, C.; Wang, F.; Zhang, G.; Huang, Z. Effects of Functionalized Graphene Nanoplatelets on the Morphology and Properties of Phenolic Resins. J. Nanomater. 2016, 2016, 1-7. [CrossRef]

48. Atchudan, R.; Edison, T.N.J.I.; Perumal, S.; Ranjithkumar, D.; Lee, Y.R. Direct growth of iron oxide nanoparticles filled multiwalled carbon nanotube via chemical vapour deposition method as high-performance supercapacitors. Int. J. Hydrog. Energy 2019, 44, 2349-2360. [CrossRef]

49. Jerng, S.-K.; Yu, D.S.; Lee, J.H.; Kim, C.; Yoon, S.; Chun, S.-H. Graphitic carbon growth on crystalline and amorphous oxide substrates using molecular beam epitaxy. Nanoscale Res. Lett. 2011, 6, 565. [CrossRef] [PubMed]

50. Zhang, Y.; Liu, J.-Y.; Ma, S.; Zhang, Y.-J.; Zhao, X.; Zhang, X.-D.; Zhang, Z.-D. Synthesis of PVP-coated ultra-small Fe3O4 nanoparticles as a MRI contrast agent. J. Mater. Sci. Mater. Med. 2010, 21, 1205-1210. [CrossRef] [PubMed]

51. Atchudan, R.; Edison, T.N.J.I.; Perumal, S.; Lee, Y.R. Green synthesis of nitrogen-doped graphitic carbon sheets with use of Prunus persica for supercapacitor applications. Appl. Surf. Sci. 2017, 393, 276-286. [CrossRef]

52. Bhangare, B.; Jagtap, S.; Ramgir, N.; Waichal, R.; Muthe, K.P.; Gupta, S.K.; Gadkari, S.C.; Aswal, D.K.; Gosavi, S. Evaluation of Humidity Sensor Based on PVP-RGO Nanocomposites. IEEE Sens. J. 2018, 18, 9097-9104. [CrossRef]

53. Atchudan, R.; Edison, T.N.J.I.; Lee, Y.R. Nitrogen-doped carbon dots originating from unripe peach for fluorescent bioimaging and electrocatalytic oxygen reduction reaction. J. Colloid Interface Sci. 2016, 482, 8-18. [CrossRef]

54. Karthikeyan, S.; Boopathy, R.; Sekaran, G. In situ generation of hydroxyl radical by cobalt oxide supported porous carbon enhance removal of refractory organics in tannery dyeing wastewater. J. Colloid Interface Sci. 2015, 448, 163-174. [CrossRef]

55. Xian, J.; Hua, Q.; Jiang, Z.; Ma, Y.; Huang, W. Size-Dependent Interaction of the Poly(N-vinyl-2-pyrrolidone) Capping Ligand with Pd Nanocrystals. Langmuir 2012, 28, 6736-6741. [CrossRef]

56. Liu, N.; Luo, F.; Wu, H.; Liu, Y.; Zhang, C.; Chen, J. One-Step Ionic-Liquid-Assisted Electrochemical Synthesis of Ionic-LiquidFunctionalized Graphene Sheets Directly from Graphite. Adv. Funct. Mater. 2008, 18, 1518-1525. [CrossRef]

57. Karthikeyan, S.; Magthalin, C.J.; Mandal, A.B.; Sekaran, G. Controlled synthesis and characterization of electron rich iron(iii) oxide doped nanoporous activated carbon for the catalytic oxidation of aqueous ortho phenylene diamine. RSC Adv. 2014, 4, 19183-19195. [CrossRef]

58. Sayah, A.; Habelhames, F.; Bahloul, A.; Nessark, B.; Bonnassieux, Y.; Tendelier, D.; El Jouad, M. Electrochemical synthesis of polyaniline-exfoliated graphene composite films and their capacitance properties. J. Electroanal. Chem. 2018, 818, 26-34. [CrossRef]

59. Shao, G.; Lu, Y.; Wu, F.; Yang, C.; Zeng, F.; Wu, Q. Graphene oxide: The mechanisms of oxidation and exfoliation. J. Mater. Sci. 2012, 47, 4400-4409. [CrossRef]

60. Salles, T.H.C.; Lombello, C.B.; D'ávila, M.A. Electrospinning of Gelatin/Poly (Vinyl Pyrrolidone) Blends from Water/Acetic Acid Solutions. Mater. Res. 2015, 18, 509-518. [CrossRef]

61. Ochal, P.; De La Fuente, J.L.G.; Tsypkin, M.; Garcia-Rodriguez, S.; Seland, F.; Sunde, S. CO-Stripping at Ru Nanoparticles. ECS Trans. 2010, 28, 9-17. [CrossRef] 
62. Alibe, I.M.; Matori, K.A.; Sidek, H.A.A.; Yaakob, Y.; Rashid, U.; Alibe, A.M.; Zaid, M.H.M.; Nasir, S.; Nasir, M.M. Effects of polyvinylpyrrolidone on structural and optical properties of willemite semiconductor nanoparticles by polymer thermal treatment method. J. Therm. Anal. Calorim. 2019, 136, 2249-2268. [CrossRef]

63. Chen, M.-L.; Park, C.-Y.; Oh, W.-C.; Meng, Z.-D.; Zhu, L.; Choi, J.-G.; Ghosh, T.; Kim, I.-J.; Yang, S.; Bae, M.-K.; et al. Characterization of Graphene Nanosheets as Electrode Material and Their Performances for Electric Double-Layer Capacitors. Fuller. Nanotub. Carbon Nanostruct. 2013, 21, 525-536. [CrossRef]

64. Zhao, X.; Zheng, B.; Huang, T.; Gao, C. Graphene-based single fiber supercapacitor with a coaxial structure. Nanoscale 2015, 7, 9399-9404. [CrossRef] [PubMed]

65. Thirukumaran, P.; Atchudan, R.; Parveen, A.S.; Lee, Y.R.; Kim, S.-C. Polybenzoxazine originated N-doped mesoporous carbon ropes as an electrode material for high-performance supercapacitors. J. Alloys Compd. 2018, 750, 384-391. [CrossRef]

66. Senthilkumar, S.T.; Kim, J.; Huang, H.; Wang, Y. Flexible and wearable fiber shaped high voltage supercapacitors based on copper hexacyanoferrate and porous carbon coated carbon fiber electrodes. J. Mater. Chem. A 2016, 4, 4934-4940. [CrossRef]

67. Li, S.; Chen, Y.; He, X.; Mao, X.; Zhou, Y.; Xu, J.; Yang, Y. Modifying Reduced Graphene Oxide by Conducting Polymer Through a Hydrothermal Polymerization Method and its Application as Energy Storage Electrodes. Nanoscale Res. Lett. 2019, 14, 1-12. [CrossRef]

68. Atchudan, R.; Edison, T.N.J.I.; Perumal, S.; Parveen, A.S.; Lee, Y.R. Electrocatalytic and energy storage performance of bio-derived sulphur-nitrogen-doped carbon. J. Electroanal. Chem. 2019, 833, 357-369. [CrossRef] 